\title{
Application of Energy Saving and Environmental Protection Green Decoration Materials in Building Construction
}

\author{
Xue Su Ling \\ School of Civil Engineering, Jiaozuo University, Jiaozuo, Henan, China
}

\begin{abstract}
:
In recent years, ecological environment protection is a hot topic in the world. The construction industry is one of the industries with large energy consumption, accounting for more than $20 \%$ of the total social production energy consumption. Conforming to the requirements of environmental protection in the construction of green decoration materials is the development of the times. In this paper, a construction project as the research object, the construction site of hydrogen sulfide, sulfur dioxide and other gas pollution, solid pollution, water pollution, light pollution and noise pollution source monitoring. The monitoring results show that the content of ammonia is the largest among the gases produced by construction, and other gases are basically below or equal to the standard limit value. The environmental problems caused by different pollution sources are analyzed. The results show that through the overall design of green building energy conservation and environmental protection, the optimization design of green building structure and the HVAC design of green building, the high quality construction of green building can be realized.
\end{abstract}

Keywords: Ecological Environment Protection, Construction Industry, Pollution Source Monitoring, Green Building.

\section{INTRODUCTION}

At present, with the rapid development of urban construction, the ecological environment problems derived from construction are gradually highlighted [1-2]. The negative impact of environmental pollution problems such as particle pollution, water pollution and light pollution during construction on environmental governance is more and more serious. As the living space of human beings, the environment's regeneration performance has become worse and worse. The vulnerability of ecological environment will bring a direct threat to human survival and sustainable development. Ecological environmental protection has long been included in China's construction [3]. For the construction industry, the damage to the environment can be divided into loss of the environment and pollution of the environment. These two problems will pose a threat to the global ecological environment [4-6]. The environmental pollution caused by the construction of all aspects, if a single or limited number of construction projects are analyzed, it will be found that the damage to the environment caused by construction is not big, but with the acceleration of urbanization, the ecological problems brought by construction to the environment will continue to increase. 


\section{ANALYSIS OF ENVIRONMENTAL POLLUTION CAUSED BY CONSTRUCTION}

Taking a construction project in a city as the research object, the total area of the project is $400000 \mathrm{~m}^{2}$, which is a high-grade residential area [7]. Take a part of the construction area of the building as an example for research and analysis, as shown in Figure 1.

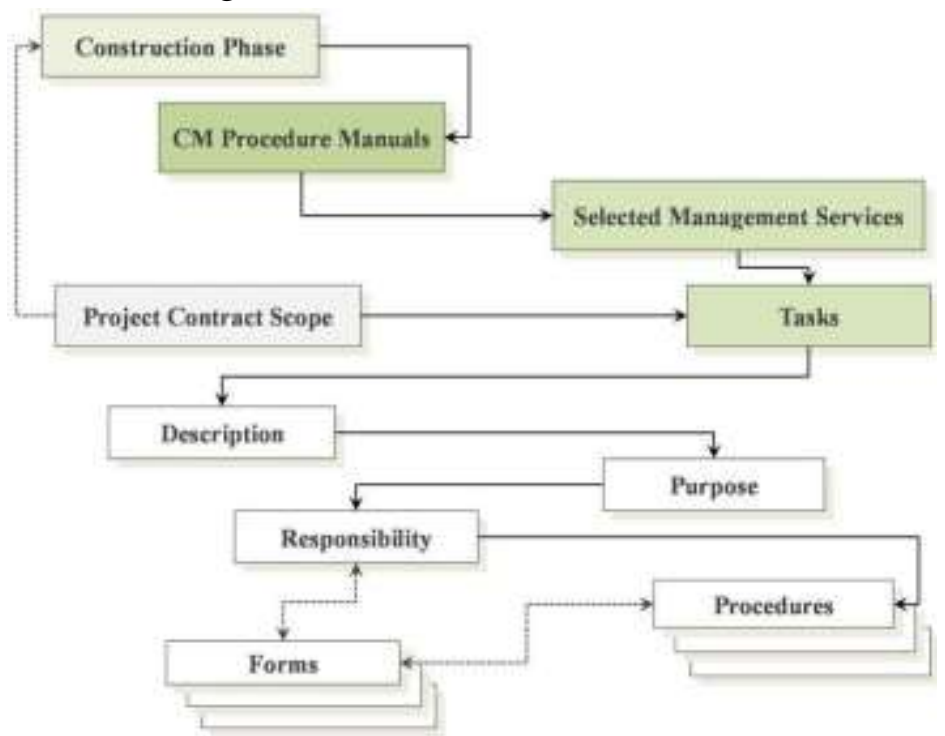

Fig 1: Construction diagram

According to the site conditions, through preliminary research and analysis, the construction site of hydrogen sulfide, sulfur dioxide, carbon dioxide and other gas pollution, solid pollution, water pollution, light pollution, noise pollution and other pollution sources are monitored.

The monitoring results of gas generated in construction are as follows [8-10]:

Based on the field sampling situation, the environmental background value was not obtained in all the monitoring items except ammonia. In the process of field monitoring, the source of ammonia was analyzed. In the construction, the concrete admixture is usually mixed in the concrete to achieve antifreeze protection. Among them, the admixtures are mainly made of urea and ammonia water as raw materials. Due to environmental changes, these additives are reduced to ammonia gas in the wall, which will be gradually released from the wall, resulting in the increasing concentration of ammonia gas in the construction site, resulting in the pollution of the ecological environment.

Table 1 shows the results of field sampling and analysis

TABLE I. Field sampling and analysis results

\begin{tabular}{|c|c|c|c|c|}
\hline $\begin{array}{c}\text { SERIAL } \\
\text { NUMBER }\end{array}$ & PROJECT & $\begin{array}{c}\text { TESTING } \\
\text { INSTRUMENT }\end{array}$ & RESULT & OTHER \\
\hline 1 & $\mathrm{H}_{2} \mathrm{O}$ & PGM-2400 & $<0.2 \mathrm{ppm}$ & LOWER THAN LIMIT \\
\hline 2 & $\begin{array}{c}\text { OXYGEN } \\
\text { CONTENT }\end{array}$ & DITTO & $21 \%$ & $\begin{array}{c}\text { SAME AS THE } \\
\text { OXYGEN CONTENT } \\
\text { IN THE } \\
\text { ATMOSPHERE }\end{array}$ \\
\hline 3 & $\mathrm{SO}_{2}$ & DITTO & $<0.2 \mathrm{ppm}$ & LOWER THAN LIMIT \\
\hline
\end{tabular}


Article History: Received: 20 October 2020, Revised: 15 November 2020, Accepted: 08 December 2020, Publication: 28 February 2021

\begin{tabular}{|c|c|c|c|c|}
4 & NO & PGM-1140 & $<0.2 \mathrm{ppm}$ & LOWER THAN LIMIT \\
\hline 5 & $\mathrm{CO}$ & GXH-3010E & $<0.2 \mathrm{ppm}$ & LOWER THAN LIMIT \\
\hline 6 & $\mathrm{CO}_{2}$ & PGM-1130 & $1.800 \mathrm{mg} / \mathrm{m}^{3}$ & LOWER THAN LIMIT \\
\hline 7 & AMMONIA & AIR SAMPLER & $3.0 \mathrm{mg} / \mathrm{m}^{3}$ & $\begin{array}{c}\text { SPECIFIED LIMIT } \leq \\
0.2 \mathrm{MG} / \mathrm{M}^{3}\end{array}$ \\
\hline 8 & EQUIVALENCE & $\begin{array}{c}\text { 451 P PATROL } \\
\text { RATE }\end{array}$ & $\begin{array}{c}0.008 \mu \mathrm{Sv} / \mathrm{h}- \\
0.017 \mu \mathrm{Sv} / \mathrm{h}\end{array}$ & $\begin{array}{c}\text { IT IS CLOSE TO THE } \\
\text { ENVIRONMENTAL } \\
\text { BACKGROUND } \\
\text { VALUE }\end{array}$ \\
\hline
\end{tabular}

It can be seen from table 1 that among the gases produced by building construction, ammonia has the largest content. Its fermentation in the air will have a greater impact on the air quality, and then affect the quality of human life.

The analysis of solid pollution, noise pollution, light pollution and water pollution in construction is shown in Table 2:

TABLE II. Cause analysis of other construction pollution

\begin{tabular}{|c|c|}
\hline PROJECT & CAUSES \\
\hline $\begin{array}{c}\text { SOLID } \\
\text { POLLUTION }\end{array}$ & $\begin{array}{l}\text { residual solid wastes such as soil, sand and cement in } \\
\text { construction }\end{array}$ \\
\hline $\begin{array}{c}\text { SOUND } \\
\text { POLLUTION }\end{array}$ & excavators, carriers and carriers and cutters \\
\hline $\begin{array}{c}\text { LIGHT } \\
\text { POLLUTION }\end{array}$ & $\begin{array}{l}\text { the "never night city" phenomenon is caused by the lighting } \\
\text { produced during construction and the small sun used by } \\
\text { workers }\end{array}$ \\
\hline $\begin{array}{c}\text { WATER } \\
\text { POLLUTION }\end{array}$ & sewage from construction and leakage of water pipes \\
\hline
\end{tabular}

The noise pollution in Table 2 is a tricky problem in environmental pollution, and it is also the construction pollution problem with the strongest response of residents. At present, some noise produced by most reinforced concrete in mixing and pouring is one of the sources of noise pollution. In addition, it also includes noise generated by the working of excavator, carrier and cutter.

The light pollution in Table 2 is mainly caused by the interference of lighting light on the lives of nearby residents during night construction. During the night construction, the small sun of the construction personnel will produce certain light, causing light pollution.

The water pollution in Table 2 mainly refers to the domestic sewage, flushing, overflow and water pipe leakage caused by the construction personnel during production.

The solid pollution in Table 2 is a relatively traditional pollution mode, which mainly includes the waste soil during land leveling, the residual soil and sand and other construction wastes generated during construction; the domestic garbage brought by construction personnel during the construction cleaning.

Figure 2 is the schematic diagram of light pollution, water pollution and solid pollution in construction. 


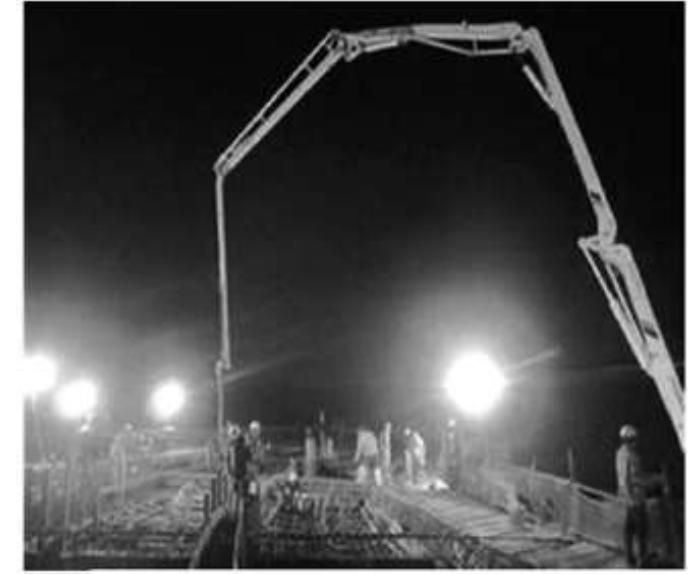

(a) Light pollution in construction

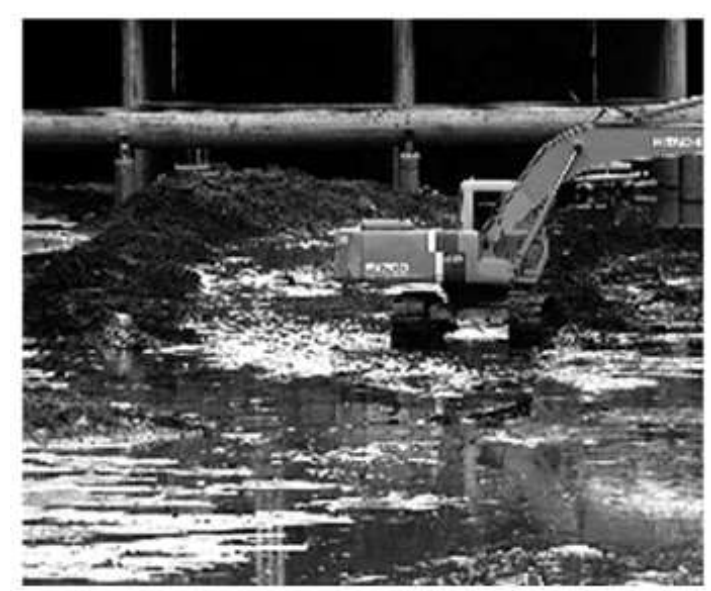

(b) Water pollution in construction

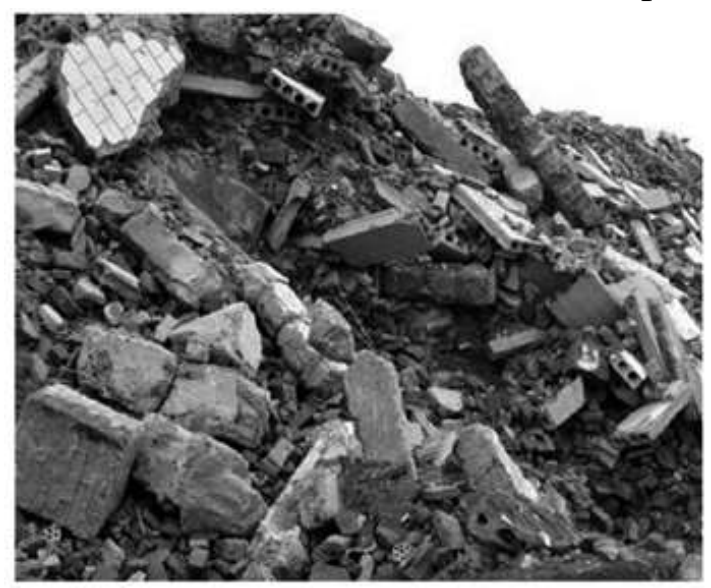

(c) Solid pollution in construction

Fig 2: Pollution caused by construction

\section{APPLICATION OF CONSTRUCTION EMISSION REDUCTION TECHNOLOGY IN ENVIRONMENTAL POLLUTION CONTROL}

Table 2 has divided the pollution caused by construction into solid pollution, gas pollution, water pollution, light pollution and noise pollution. In this paper, we use certain emission reduction technology to control the above aspects of environmental pollution.

3.1 Water pollution control in construction

1) Reduce liquid pollution during construction

New construction methods, relatively advanced construction equipment and less toxic chemicals are adopted to minimize water pollution in construction.

2) Recycling of pollutants

Recycling of pollutants generated in construction refers to the proper use of pollutants in the construction site within its own scope, and the re allocation and use of the original water pollutants to be treated, so as to change the original "waste" of pollutants into "non waste". Construction sites often cause large-scale sewage overflow due to construction. If the relevant sewage is reused and the pollutants are absorbed on the construction site, it can not only reduce the discharge of pollutants, but also save water. Examples of recycling 
pollutants on the construction ground are drilling cooling water and pile grinding water.

3) Recycling of pollutants

Recycling of pollutants generated in construction refers to the proper use of pollutants in the construction site within its own scope, and the re allocation and use of the original water pollutants to be treated, so as to change the original "waste" of pollutants into "non waste". Construction sites often cause large-scale sewage overflow due to construction. If the relevant sewage is reused and the pollutants are absorbed on the construction site, it can not only reduce the discharge of pollutants, but also save water. Examples of recycling pollutants on the construction ground are drilling cooling water and pile grinding water.

4) Centralized treatment of sewage generated by construction

The discharge point or end treatment point in construction refers to the final treatment position before construction pollutant discharge, as shown in Figure 3. According to the establishment of sewage points, improving the quality of sewage, and then discharging, which is a common way of water pollution control in construction. Although the pollutant emission location is a remedial strategy, it can have an immediate effect.

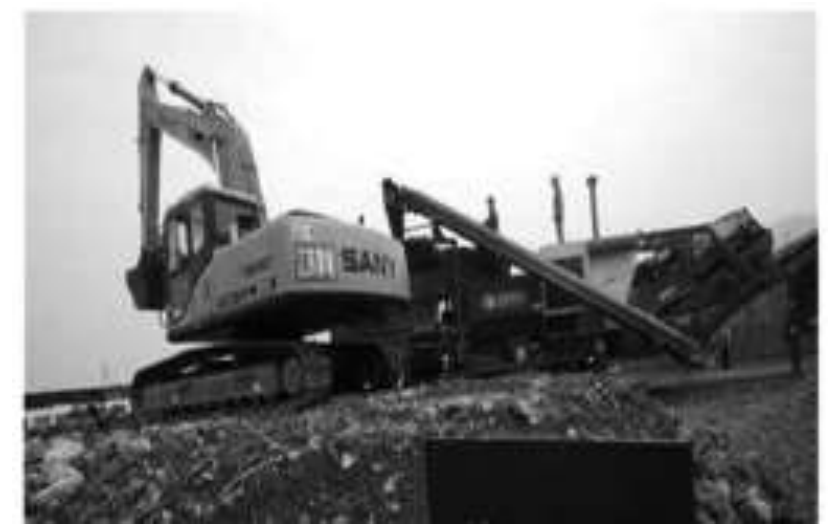

Fig 3: Construction waste discharge point

5) Orderly discharge of construction sewage

6) Prevention of leakage of liquid organic matter

3.2 Solid pollution control in construction

(1) build a temporary steel recycling plant at the construction site to treat the remaining steel and other pollutants in real time, so as to achieve the effect of emission reduction.

(2) the remaining construction materials, such as construction equipment and sand, shall be cleared out of the construction site according to the plan.

(3) use the wall isolation method to limit the pollutants in a range to prevent the diffusion of pollutants.

3.3 Noise pollution control in construction

The noise pollution produced in the construction will cause adverse effects on the builders themselves and the surrounding residents. Because of the complexity of the construction process, a lot of construction machinery and equipment are used. In order to reduce noise pollution, the emission reduction measures are as follows:

(1) during the construction process, the procedures with high noise shall be arranged in the daytime as far as possible to avoid the impact on nearby residents. For the power type construction equipment, the equipment should be reasonably configured to avoid the situation that this type of equipment is concentrated in a certain area.

(2) in the process of construction, the large mechanical equipment used should be parked far away from 
the residential area.

(3) for the construction equipment whose noise is higher than the national standard, it is necessary to reduce the noise pollution by means of silencing equipment and measures.

(4) for the vehicles used in the construction process, special silencing equipment or instruments should be set up, and the whistle can only be sounded in the construction area.

3.4 Gas pollution control in construction

(1) improve the surface properties of fugitive dust during construction. In the process of stacking and transporting fugitive materials, plants, water and cloth cover are used to deal with the fugitive dust, which can effectively prevent the dust pollution in the air.

(2) select the construction machinery with less pollution. At present, most of the construction methods are mechanical operation, which improves the work efficiency, but its own gaseous substances will pollute the environment. In order to reduce the pollution caused by this phenomenon, we should properly reduce the use of such equipment, properly arrange and study the types of relevant construction machinery, reduce the use of fuel machinery, and then reduce the impact of gas in construction on the environment.

(3) control the materials used in construction, and use more environmental protection building materials. There are a lot of materials used in building construction. However, when these materials are used, gases containing chemical substances such as sulfur or ammonia are often produced. In view of this situation, the environmental management of the construction site needs to comply with the relevant regulations. For example: select fuel with low sulfur content to reduce $\mathrm{SO}_{2}$ emission.

3.5 Light pollution control in construction

Adjust the time in construction and try to avoid working at night. If it is necessary to carry out construction at night, the lighting direction should be reasonably adjusted, not only to ensure the lighting in the construction process, but also to avoid the impact on nearby residents and reduce light pollution.

\section{CONCLUSION}

In the face of the current development situation, it has become an unshirkable responsibility for social development to minimize the impact of construction on the environment, reduce environmental pollution and do a good job in environmental pollution control. The application of construction emission reduction technology in environmental pollution control can effectively solve the current environmental pollution problems caused by poor construction. This paper studies the application of building construction emission reduction technology in environmental pollution control, finds out the main environmental problems existing in building construction, and takes the solid pollution, gas pollution, water pollution, light pollution and noise pollution in building construction as the objects, and realizes the treatment and improvement of ecological environment through different technical means.

\section{REFERENCES}

[1] Kim, Gwang Hee, H. M. Song, and Y. S. Shin. "A Case Study on the Use of Aluminum Forms in Nuclear Power Plant Construction." Advanced Materials Research 919-921.919-921(2014):296-299.

[2] Marsh, Cedric. "Fifty Years of Aluminum in Construction." Journal of the Construction Division 101(1975):583592. 
[3] Xie, Hui, et al. "Lithium Distribution in Aluminum-Free Cubic Li7La3Zr2O12." ChemInform 42.44(2011):35873589.

[4] Tam, Vivian W. Y., and C. M. Tam. "Evaluations of existing waste recycling methods: A Hong Kong study." Building \& Environment 41.12(2006):1649-1660.

[5] Defraeye, Thijs, et al. "Forced-convective cooling of citrus fruit: Cooling conditions and energy consumption in relation to package design." Journal of Food Engineering 121(2014):118-127.

[6] Berrada, A., K. Loudiyi, and I. Zorkani. "Sizing and economic analysis of gravity storage." Journal of Renewable \& Sustainable Energy 8.2(2016):824-829.

[7]Papaphilippou, C., et al. "Surface aluminum alloy formation by electrodeposition from alkali chloride melts and by laser techniques." Acta Metallurgica Et Materialia 40.7(1992):1691-1698.

[8] Rath, Surya Kumar Dube, Girija Prasad. "Application of Valsalva manoeuvre to facilitate resection of intradiploic arachnoid cyst." Indian Journal of Anaesthesia 58.4(2014):490-1.

[9] Lin, C. H., et al. "Self-consolidating concrete columns under concentric compression." Aci Structural Journal 105.4(2008):425-432.

[10] Cheng, Lijuan, and V. M. Karbhari. "Design approach for a FRP structural formwork based steel-free modular bridge system." Structural Engineering \& Mechanics 24.5(2006):561-584. 